\title{
Microoxygraph Device for Biosensoristic Applications
}

\author{
A. Aloisi, ${ }^{1}$ E. Tarentini, ${ }^{1}$ A. Ferramosca, ${ }^{2}$ V. Zara, ${ }^{2}$ and R. Rinaldi ${ }^{1,3}$ \\ ${ }^{1}$ Euromediterranean Center for Nanomaterial Modelling and Technology (ECMT) of Consiglio Nazionale delle Ricerche (CNR), \\ Institute of Nanoscience, 73100 Lecce, Italy \\ ${ }^{2}$ Biological and Environmental Sciences and Technologies Department (DiSTeBA), University of Salento, 73100 Lecce, Italy \\ ${ }^{3}$ Mathematics and Physics "E. De Giorgi” Department, University of Salento, 73100 Lecce, Italy
}

Correspondence should be addressed to A. Aloisi; alessandra.aloisi@nano.cnr.it and R. Rinaldi; ross.rinaldi@unisalento.it

Received 14 August 2015; Revised 1 November 2015; Accepted 9 November 2015

Academic Editor: Christos Tsamis

Copyright (C) 2016 A. Aloisi et al. This is an open access article distributed under the Creative Commons Attribution License, which permits unrestricted use, distribution, and reproduction in any medium, provided the original work is properly cited.

\begin{abstract}
Oxygen consumption rate (OCR) is a significant parameter helpful to determine in vitro respiratory efficiency of living cells. Oxygen is an excellent oxidant and its electrocatalytic reduction on a noble metal allows accurately detecting it. By means of microfabrication technologies, handy, low-cost, and disposable chip can be attained, minimizing working volumes and improving sensitivity and response time. In this respect, here is presented a microoxygraph device (MOD), based on Clark's electrode principle, displaying many advantageous features in comparison to other systems. This lab-on-chip platform is composed of a three-microelectrode detector equipped with a microgrooved electrochemical cell, sealed with a polymeric reaction chamber. Au working/counter electrodes and $\mathrm{Ag} / \mathrm{AgCl}$ reference electrode were fabricated on a glass slide. A microchannel was realized by photoresist lift-off technique and a polydimethylsiloxane (PDMS) nanoporous film was integrated as oxygen permeable membrane (OPM) between the probe and the microreaction chamber. Electrochemical measurements showed good reproducibility and average response time, assessed by periodic injection and suction of a reducing agent. OCR measurements on 3T3 cells, subjected, in real time, to chemical stress on the respiratory chain, were able to show that this chip allows performing consistent metabolic analysis.
\end{abstract}

\section{Introduction}

Determination of oxygen levels is required in many different research fields, such as in environmental analysis, in medical area, and in biotechnology industries, as $\mathrm{O}_{2}$ is an important physiological parameter and a nutrient for the microorganisms, plants, and yeasts used in different applications.

Matching biochips' readouts with the biological data obtained via traditional methods represents a key point for a correct analysis of the experimental results. Recently, especially in the field of novel drug screening, improved control of cell response plays a pivotal role. For quantitative understanding of these events, microbioreactors are expected opportunities to study cells under simulated physiological microenvironments, enabling spatial and temporal control of cell behaviour. To these aims combining novel structural and sensing devices into whole microsystems is required. The final devices should be minimally cell-invasive, sensitive, and rapid and of low cost, increasing in throughput and decreasing in biological sample and chemical reagents required amount for each assay. Therefore, in this study, a disposable plastic device, for cell microculture (for both suspended and adherent cells), useful in monitoring cellular metabolic state, was developed. By means of an electrochemical sensor, our device detects changes in the $\left[\mathrm{O}_{2}\right]$ gas passing through perm-selective membrane. The conventional polarographic Clark electrode consists of a Pt cathode and an $\mathrm{Ag}$ anode in contact with an electrolytic solution and separated from the measurement sample by an oxygen permeable membrane. Basically, at a constant applied potential, when the gas interchange with the external environment is excluded, cellular activity generates a decrease of the current related to the concentration of dissolved oxygen, which diffuses through the membrane, as described in the following scheme:

$$
\frac{\mathrm{d} C_{c}}{\mathrm{~d} t}=q \mathrm{O}_{2} \cdot X_{v}=\mathrm{OCR}
$$

(where $C_{c}$ is the dissolved oxygen concentration in the chamber, $t$ is the time, $q \mathrm{O}_{2}$ is the cell-specific oxygen consumption 
rate, and $X_{v}$ is the cell density [1]) and which is reduced at the cathode, according to the following chemical reaction:

$$
\mathrm{O}_{2}+4 \mathrm{H}^{+}+4 \mathrm{e}^{-} \longrightarrow 2 \mathrm{H}_{2} \mathrm{O}
$$

Traditionally, mitochondrial function has been assessed with Clark-type probe for measuring oxygen consumption [2]. Measurement of mitochondrial bioenergetics, as a useful parameter correlated with cell viability in response to different stimuli, would provide valuable insight into several disorders as well as into physiological and regenerative conditions; thus better-quality approaches to quantify cells functionality in terms of oxygen consumption over time $[3,4]$ are being studied. New generations of oxygen electrodes and oxygraphic chambers, as well as of software for the automatic analysis of respiratory kinetics, are now available [5].

In this context, the purpose of this work was to evaluate the efficiency of a new glass/PDMS made microoxygraph device (MOD) for noninvasive electrochemical OCR evaluation even of small cell samples.

Gas permeable and biocompatible soft polymers are suitable for biological applications; particularly, high intrinsic permeability to gases [6-8] is attributed to PDMS, due to the large free volume given by the flexibility of the siloxane (-SiO-) linkages; the diffusion coefficient of oxygen in PDMS is reported as $3.4 \times 10^{-5} \mathrm{~cm}^{2} \mathrm{~s}^{-1}[9,10]$ and this value is essentially in the same range as that in salt phosphate buffer (PBS) and culture medium $\left(2.1-2 \times 10^{-5} \mathrm{~cm}^{2} \mathrm{~s}^{-1}\right)$ [11]. For these reasons, untreated PDMS serves as an effective oxygen reservoir $\left(\mathrm{O}_{2}\right.$ solubility in PDMS is higher $(10.6 \mathrm{nmol} / \mathrm{mL} \mathrm{mmHg})$ [12] compared with that in culture media $(1.19 \mathrm{nmol} / \mathrm{mL} \mathrm{mmHg})$ ) [11]. Nevertheless gas permeation may change in response to its surface processing [13]. The modification of PDMS surfaces, to control the interactions between molecules and cells, and microdevice substrate has become, currently, a key technology. In this context, several amperometric miniaturized devices have been proposed [14-27]. All of the referred systems show modifications in the electrode number, materials, geometry, and dimension giving different sensing efficiency and fabricating costs as results; on a parallel route, diverse semipermeable membrane-type and microculture chamber materials, features, and required sample volume are discussed. Only few of them present useful microfluidic system. By exploiting and modulating these features, we were able to develop an optical grade biocompatible-reaction chamber with a miniaturized circular amperometric detector, connected to each other by a microfluidic system.

\section{Materials and Methods}

\subsection{Reagents and Materials}

Microelectrodes. Soda Lime glass slides $(300 \times 300 \mathrm{~mm})$ with a thickness of $1.1 \mathrm{~mm}$ were purchased from VisionTek. Sulfuric acid $\left(\mathrm{H}_{2} \mathrm{SO}_{4}\right.$, J.T. Baker) and hydrogen peroxide $\left(\mathrm{H}_{2} \mathrm{O}_{2}\right)$ were used as cleaning Piranha solution $(3: 1, \mathrm{v} / \mathrm{v}$ of $\mathrm{H}_{2} \mathrm{SO}_{4}$ and $\left.\mathrm{H}_{2} \mathrm{O}_{2}\right)$. Acetone $\left(\mathrm{C}_{3} \mathrm{H}_{6} \mathrm{O}\right)$ and 2-propanol $\left(\mathrm{CH}_{3} \mathrm{CH}(\mathrm{OH}) \mathrm{CH}_{3}\right)$ (J.T. Baker) were employed for a further washing of glass substrates and for final lift-off process. A positive reversal photoresist (AZ5214E) and its developer (AZ $726 \mathrm{MIF}$ ) (AZ Electronic Materials) were used for the photolithographic process. Gold (99.99\% granulate $0.2-0.7 \mathrm{~mm}$ ) and silver (99.99\% granulate $0.7-1.5 \mathrm{~mm}$ ) (Umicore) were used to fabricate microelectrodes. Iron(III) chloride $\left(\mathrm{FeCl}_{3}\right.$, Sigma Aldrich) solution was used for silver layer chemical chlorination.

Microchamber and Oxygen Permeable Membrane (OPM). PDMS (Sylgard 184, Dow Corning) was used to fabricate microchambers and OPM. Bovine serum albumin (BSA) and poly-L-lysine (Sigma Aldrich) were used as PDMS functionalizing molecules.

Electrolyte Microchannel. Positive photoresist (AZ40XT) and AZ 726 MIF developer (AZ Electronic Materials) were employed to realize a thick master on microelectrodes. PDMS was used to obtain the microgroove structure by dimethylsulfoxide (DMSO, Sigma Aldrich) as photoresist remover.

Electrochemical Measurements. Potassium chloride $(\mathrm{KCl})$ aqueous solution was employed as electrolyte during electrochemical measurements. Sodium dithionite $\left(\mathrm{Na}_{2} \mathrm{~S}_{2} \mathrm{O}_{4}\right)$ was used as strong oxygen reducing agent. Iron(III) chloride $\left(\mathrm{FeCl}_{3}\right)$ was used during chlorination treatment. All the reagents were from Sigma Aldrich.

Cell Culture. Murine fibroblasts (3T3) were routinely cultured in $25 \mathrm{~mL}$ T-flasks in a complete growth Dulbecco's modified Eagle's medium (DMEM) supplemented with $10 \%$ fetal bovine serum (FBS), $1 \%$ penicillin-streptomycin, and $1 \%$ glutamine (Sigma Aldrich), in a $37^{\circ} \mathrm{C}$ humidified incubator, with $5 \% \mathrm{CO}_{2}$. After trypsinization, cells were appropriately diluted, resuspended in microvolumes $\left(100 \mu \mathrm{L}, 1.8 \times 10^{4}\right.$ cells/microchamber), injected into microdevice, and incubated in controlled atmosphere within a petri dish. Just prior to $\mathrm{O}_{2}$ consumption evaluation, DMEM was replaced with complete Leibovitz medium (L15) for the maintenance of the physiological pH. $20 \mathrm{mM}$ sodium azide $\left(\mathrm{NaN}_{3}\right.$, Sigma Aldrich) aqueous solution was used as respiration inhibitor during electrochemical measurements.

2.2. Apparatus and Procedures. Microfabrication processes were performed by means of single-wafer spin processor (Model WS-400-6 NPP/LITE SHOWN, Laurell Technologies Corporation), Pico Electronic Diener plasma hasher, hot plates, bromograph, and thermal evaporation system. Single-component characterization was carried out by KLATencor, Alpha-Step IQ profilometer, and Bruker Nanoscope VI Multimode Scanning Probe workstation.

Tha assembled device was valued by Autolab, PGSTAT30 potentiostat (Metrohm) controlled by General Purpose Electrochemical System software (GPES).

Microelectrodes Fabrication. Standard photolithographic techniques were utilized to fabricate the sensor. The glass slides were cleaned by Piranha solution for $1 \mathrm{~h}$ and washed in acetone and isopropyl alcohol. The three-electrode 
circular pattern was deposited by thermal evaporation on the glass substrate: $\mathrm{Cr} / \mathrm{Au}(10 / 50 \mathrm{~nm})$ and $\mathrm{Cr} / \mathrm{Ag}(10 / 150 \mathrm{~nm})$ (Figure 2(a)). Concentrically, from the inside towards the outside are the central gold WE (500 $\mu \mathrm{m}$ diameter), the gold $\mathrm{CE},(500 \mu \mathrm{m}$ width $)$, and the silver RE $(500 \mu \mathrm{m}$ width). WE area is $0.002 \mathrm{~cm}^{2}$.

$\mathrm{Ag} / \mathrm{AgCl}$ Reference Electrode. Direct deposition of silver chloride particles was performed by chemical oxidation, inside the closed polymeric microfluidic channel. Two different published protocols were tested and compared: incubation with $50 \mathrm{mM} \mathrm{FeCl}{ }_{3}$ aqueous solution for $50 \mathrm{sec}$ [28] or with $0.1 \mathrm{M} \mathrm{FeCl}_{3}$ aqueous solution for $5 \mathrm{~min}$ [17]. Before chlorination, silver film surface was washed by 10 min sonication in ultrapure water. After that it was exposed to $0.05 \mathrm{M} \mathrm{H}_{2} \mathrm{SO}_{4}$ solution for $2 \mathrm{~min}$ to remove impurities and then rinsed again in ultrapure water for three times [29]. Following the deposition of silver chloride particles, three washes with ultrapure water were made in order to remove $\mathrm{FeCl}_{3}$ excess.

Electrolyte Microgroove Fabrication. A microfluidic system was created on the electrode-modified glass substrate, by photoresist lift-off technique [30]. Positive photoresist (AZ40XT) was utilized to obtain a $100 \mu \mathrm{m}$ thick channel shaped master on the detection area. Then a mixture of PDMS-curing agent $(20: 1)$ was spread on glass slide surface by spin coating ( $1500 \mathrm{rpm}$, for $20 \mathrm{~s}$ ) in order to obtain an $80 \mu \mathrm{m}$ thick PDMS film after polymerization at $70^{\circ} \mathrm{C}$ for $30 \mathrm{~min}$. Sonication in DMSO, for $1 \mathrm{~h}$, was performed to remove the photoresist. Once photoresist is dissolved, also the PDMS layer is removed, generating two arms $(1.6 \mathrm{~mm}$ wide and $8.5 \mathrm{~mm}$ long), connected to a semicircular groove in correspondence to the circular electrodes area (Figure 2(a), inset). Then, the slide was washed with isopropyl alcohol to eliminate DMSO excess. The patterned PDMS layer well functioned as an electrical insulation coat.

Oxygen Permeable Membrane Fabrication. Thin semipermeable nanoporous membrane (Figure 2(b)) was prepared by changing an already communicated protocol [31]. Briefly, a mixture of PDMS-curing agent $(10: 1 \mathrm{w} / \mathrm{w})$ and deionized ultrapure water, used as a porogen agent at a ratio of $50 \%$, was stirred for $30 \mathrm{~min}$ and degassed to remove any residual air bubbles. After that, it was spread on a glass substrate by spin coating $(1500 \mathrm{rpm}$, for $20 \mathrm{~s})$ and then cured at $70^{\circ} \mathrm{C}$ for $30 \mathrm{~min}$.

OPM Treatment for Cell Adhesion. In order to make it suitable for cell culturing, the membrane was subjected to a plasma $\mathrm{O}_{2}$ treatment by a plasma hasher $\left(5 \mathrm{~min}, 20 \% \mathrm{O}_{2}, 100 \mathrm{~W}\right.$, and $40 \mathrm{kHz}$ ) and incubated with $0.01 \% \mathrm{w} / \mathrm{v}$ poly-L-lysine for $30 \mathrm{~min}$ (extracellular matrix proteins might also be used); this treatment is meant to promote cell adhesion on the polymeric membrane.

Atomic Force Microscopy. Silver chloride particles and OPM surface images were recorded in air at RT using a Nanoscope V PicoForce MultiMode (Bruker Corp., USA), operating in tapping mode with phosphorus doped silicon cantilevers, tip radius of $8 \mathrm{~nm}$, and resonance frequency of $69-92 \mathrm{kHz}$ (probe model R FESPA, Bruker Corp., USA). A $(15 \times 15) \mu \mathrm{m} \mathrm{E}$ type scanner and scan rate at $1.5 \mathrm{~Hz}$ were used. Nanoscope software v7.30 (Bruker Corp., USA) tool roughness was applied to obtain RE electrode superficial roughness average values; section tool was applied to obtain OPM pores' major axis size.

Microoxygraph Chamber Fabrication. The microreaction chamber $(7 \mathrm{~mm}$ height, $9 \mathrm{~mm}$ outer diameter, and $6 \mathrm{~mm}$ inner diameter) was made with PDMS/curing agent mixture $(1: 10 \mathrm{w} / \mathrm{w})$, casted in appositely fabricated steel molds, and incubated at $70^{\circ} \mathrm{C}$ for $90 \mathrm{~min}$. A mini column holder was utilized to sustain a capillary on the top of cast, upholding over the time required for PDMS polymerization. In this way microchamber was equipped with an upper inlet $(1 \mathrm{~mm}$ diameter), useful for easy sample or drug injection. The microchamber, which is open towards the sensor, is a single piece with a $4 \mathrm{~mm}$ thick PDMS slab. This modulus was bonded to the underlying OPM and electrolyte groove, preventing oxygen exchange with the external environment. Inlet and outlet holes were made in correspondence with the ends of the microgroove arms as component of the microfluidic system, useful to inject and withdraw reagents and electrolytes solutions in/from the microchannel.

Chamber Insulation. Closed microoxygraph chamber must prevent oxygen exchange with the external environment, so that the only oxygen present in the chamber is reduced at the cathode during measurements. It was demonstrated that native PDMS is highly oxygen permeable and the permeability changes when proteins are adsorbed on it or when surface is modified by plasma oxidation. After $5 \mathrm{~min}$ plasma oxidation mass-transfer coefficient of oxygen through PDMS is reduced by 1000 -fold; a 5 times decrease is obtained after incubation with bovine serum albumin $[25,32,33]$. According to this knowledge we have exposed the inner and outer microchamber walls at $\mathrm{O}_{2}$ plasma by a plasma hasher ( $5 \mathrm{~min}, 20 \% \mathrm{O}_{2}, 100 \mathrm{~W}, 40 \mathrm{kHz}$ ) and then functionalized by incubation of $0.01 \% \mathrm{w} / \mathrm{v}$ BSA for $1 \mathrm{~h}$.

Plasma Bonding. Based on a previous work [34], we obtained optimal PDMS-PDMS adhesion strength by the sequent parameters: exposure time $2 \mathrm{~min}$; oxygen gas flow $10 \%$; power $20 \mathrm{~W}$; and pressure $0.6 \mathrm{mbar}$. Plasma-treated surfaces were immediately bonded and then baked in oven under a weight pressure, at $70^{\circ} \mathrm{C}$ for $1 \mathrm{~h}$.

2.3. Preprocessing of the Sensor. The detector surface is processed just before starting measurement. Through the microfluidic system, $0.05 \mathrm{M} \mathrm{H}_{2} \mathrm{SO}_{4}$ solution was dispensed to remove excess impurities for 2 minutes; this procedure was repeated for three times. After $\mathrm{H}_{2} \mathrm{SO}_{4}$ suction, the excess was removed by injection of ultrapure water for three times. Finally, $\mathrm{FeCl}_{3}$ solution was injected to fill the microchannel and allowed to react with the silver film for $50 \mathrm{sec}$. After cleaning steps, the sensing area was rinsed with ultrapure water; then, $0.1 \mathrm{M} \mathrm{KCl}$ electrolyte aqueous solution was dispensed in the microgroove. MOD was connected to potentiostat 


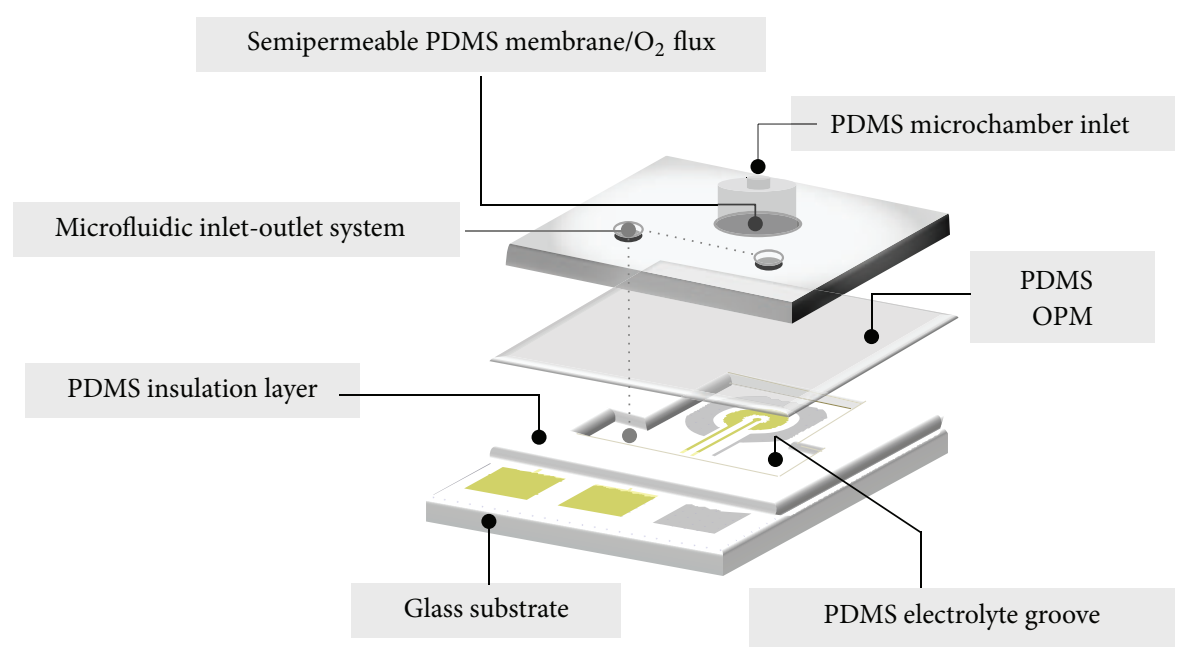

FIGURE 1: Graphical representation of microoxygraph device components' layout.

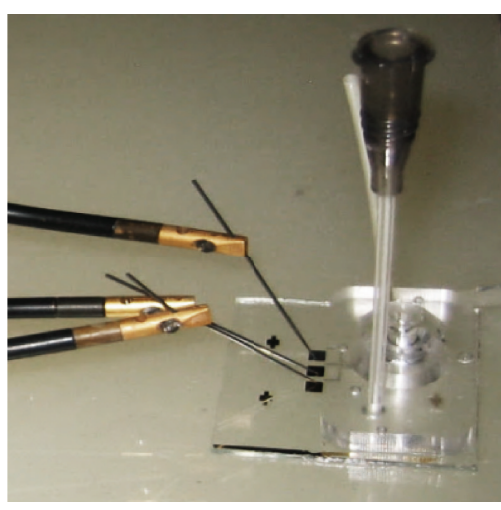

(a)

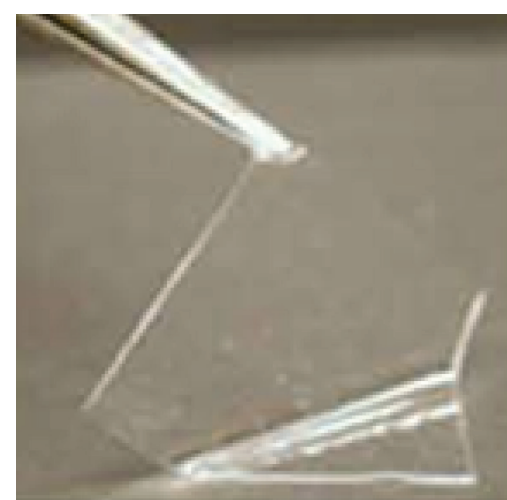

(b)

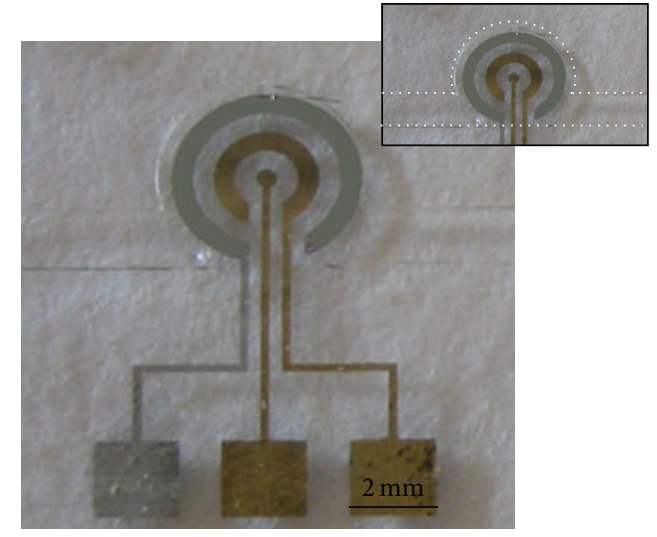

(c)

Figure 2: Assembled microoxygraph device. Potentiostat connection by micromanipulators (a). Semipermeable PDMS membrane, $80 \mu \mathrm{m}$ thick (b). Fabricated planar concentric microelectrodes; electrolyte PDMS microgroove is highlighted (inset, white line (c)).

by micromanipulators aided microtip positioned on the electrode pads (Figure 2(a)). Amperometric measurements were carried out at an applied potential of $-0.8 \mathrm{~V}$ versus $\mathrm{Ag} / \mathrm{AgCl}$.

\section{Results and Discussion}

The presented MOD consists of a three-microelectrode detector on a glass substrate, an electrical insulation layer with a selective opening, and the PDMS microchamber modulus [35], separated by a nanoporous PDMS OPM; a microfluidic system connects the electrolyte container placed on sensing microelectrode area (Figure 1).

3.1. Microelectrodes Fabrication. The fabricated microelectrodes system is shown in Figure 2(c). Detailed information about chlorination effects on silver layer was recorded by AFM scan performed in tapping mode. Reaction with $0.1 \mathrm{M}$ $\mathrm{FeCl}_{3}$ for $5 \mathrm{~min}$ produces a homogeneous $\mathrm{Ag} / \mathrm{AgCl}$ layer in which some growth nuclei are visible (Figure 3(b)). Particles are easily distinguishable in Figure 3(c) that shows $\mathrm{Ag} / \mathrm{AgCl}$ layer grown by $50 \mathrm{mM} \mathrm{FeCl}_{3}$ for $50 \mathrm{sec}$. Morphological appearances were confirmed by statistical analysis of the superficial roughness average values $\left(R_{a}\right)$ representing the arithmetic average of absolute values of surface height deviations measured from the mean plane and $R_{q}$ representing the root mean square average of height deviations taken from the mean image data plane (Table 1).

Both parameters' values show the presence of $\mathrm{Ag} / \mathrm{AgCl}$ layer; however a rougher particulate layer grew after reaction with $50 \mathrm{mM} \mathrm{FeCl}_{3}$ for $50 \mathrm{sec}$ treatment. A microreference electrode, with higher $\mathrm{Ag} / \mathrm{AgCl}$ layer thickness as well as silver chloride particles higher surface area, is expected to exhibit increased stability as reported by [28]; thus, the latter protocol was selected as the working procedure. Internal control was performed on gold electrode surface which did not undergo changes after treatment (image not shown): the superficial roughness average values $\left(R_{a}\right.$ and $\left.R_{q}\right)$ remained relatively unchanged (Table 1). 


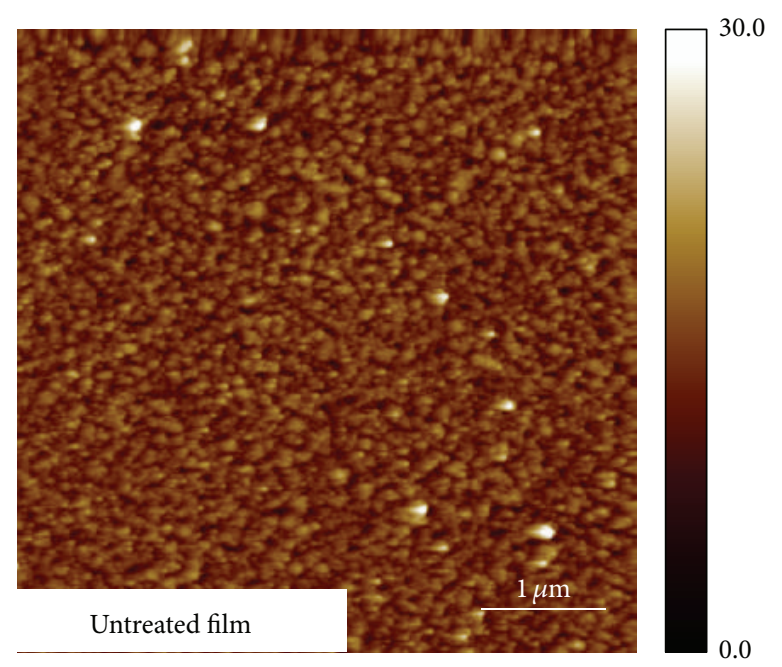

(a)

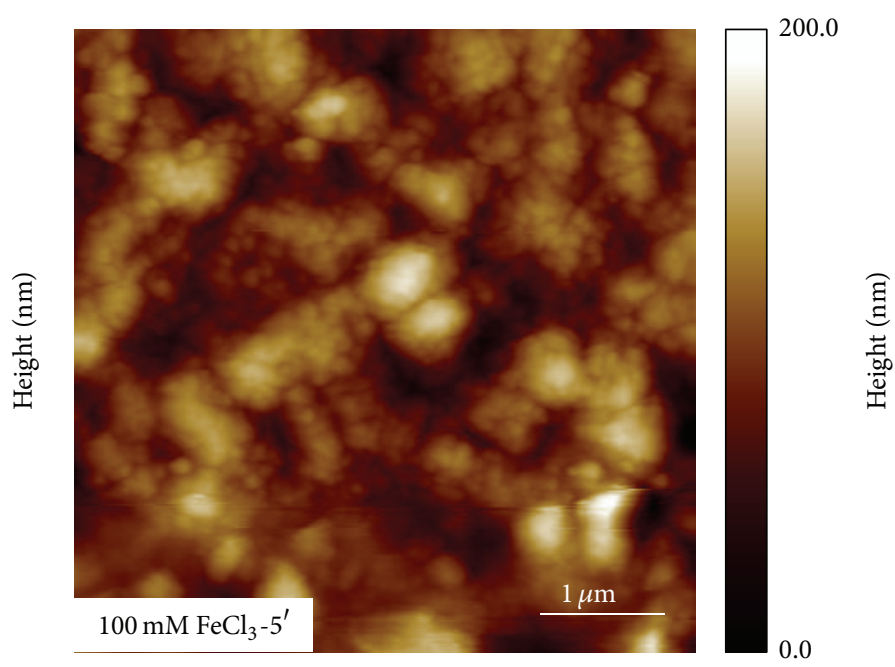

(b)

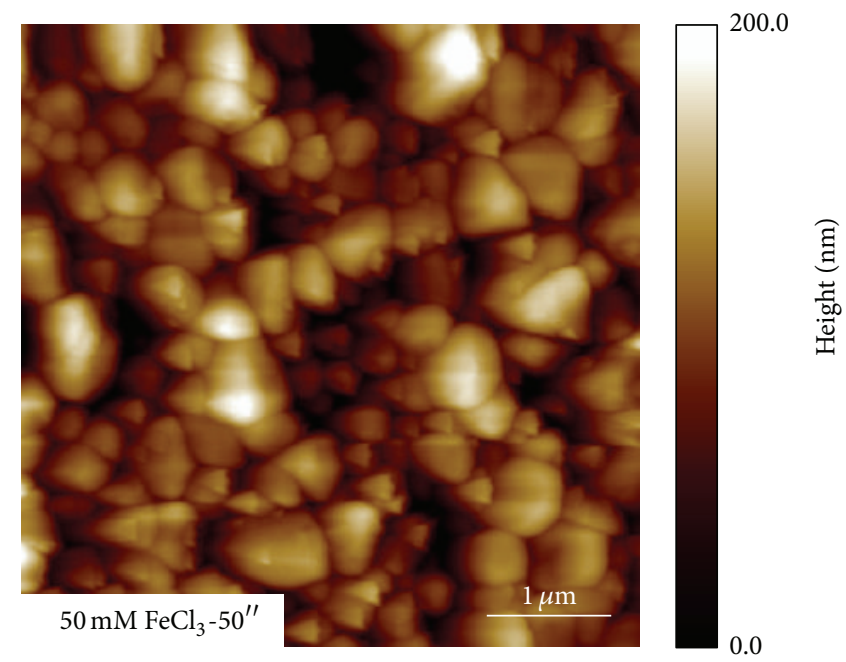

(c)

FIGURE 3: AFM topographic characterization of silver layer. AFM images of untreated silver layer (a); $\mathrm{Ag} / \mathrm{AgCl}$ layer grown by $0.1 \mathrm{M}$ FeCl ${ }_{3}$ for $5 \mathrm{~min}$ (b) or by $50 \mathrm{mM} \mathrm{FeCl}_{3}$ for $50 \mathrm{sec}$ (c). Scan size, $5 \mu \mathrm{m}$.

OPM Characterization. The achieved PDMS membrane, of $80 \mu \mathrm{m}$ thickness, as assessed from profilometer scansion, presented randomly distributed pores with major diameter of $(204 \pm 118) n m$ expressed as means \pm SD $(n=60)$, as evaluated by AFM scansion performed in tapping mode, in air (Figures $4(\mathrm{a})$ and $4(\mathrm{~b}))$. Cell adhesion on the OPM, after $24-48 \mathrm{~h}$ of incubation, was valued by optical microscopy. A monolayer of confluent cells is clearly visible (Figure 4(c)).

\subsection{Microoxygraph Functionality}

3.2.1. Characteristics of Miniature Oxygen Sensor. Firstly, the electrochemical behavior of electrode system was investigated. Figure 5 shows the typical cyclic voltammogram of oxygen reduction occurring in the MOD with an electrolyte solution of $0.1 \mathrm{M} \mathrm{KCl}$. Cyclic voltammetry of the miniaturized sensor was performed with a water-filled microchamber, at a scan rate of $50 \mathrm{mVs}^{-1}$ and a potential range set from 0 to
$-1 \mathrm{~V}$ versus $\mathrm{Ag} / \mathrm{AgCl}$. The microsensor showed a distinctive peak current around $-0.8 \mathrm{~V}$ (Figure 6); thus, the subsequent amperometric detection of different dissolved oxygen concentrations was carried out, at room temperature, with an applied potential of $-0.8 \mathrm{~V}$ versus $\mathrm{Ag} / \mathrm{AgCl}$.

Repetitively, tests were performed to analyze electrochemical functionality and response time of the threemicroelectrode configuration as well as the solidity and reproducibility (strictly related to the potential stability of the reference electrode and the crosstalk effect between the three electrodes of the electrochemical detector [23]).

Experimentally, $0.1 \mathrm{M} \mathrm{Na}_{2} \mathrm{~S}_{2} \mathrm{O}_{4}$ solution was employed as strong oxygen reducing agent to stabilize a zero-oxygen concentration condition. Microoxygraph response was evaluated by periodic injection and suction of $\mathrm{Na}_{2} \mathrm{~S}_{2} \mathrm{O}_{4}$ solution from microoxygraph chamber inlet. In Figure 6 the reduction current results in saturated and zero-oxygen concentration conditions are plotted. Each measurement was performed 


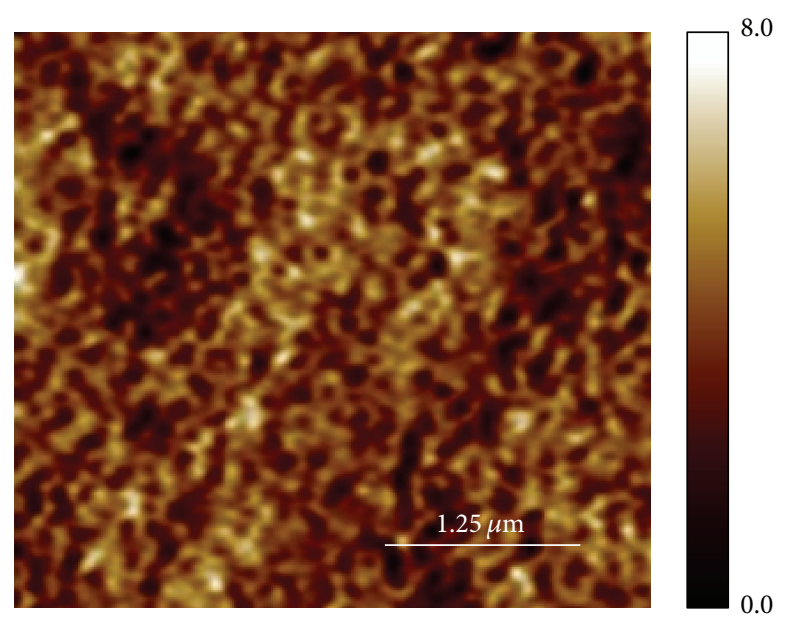

(a)

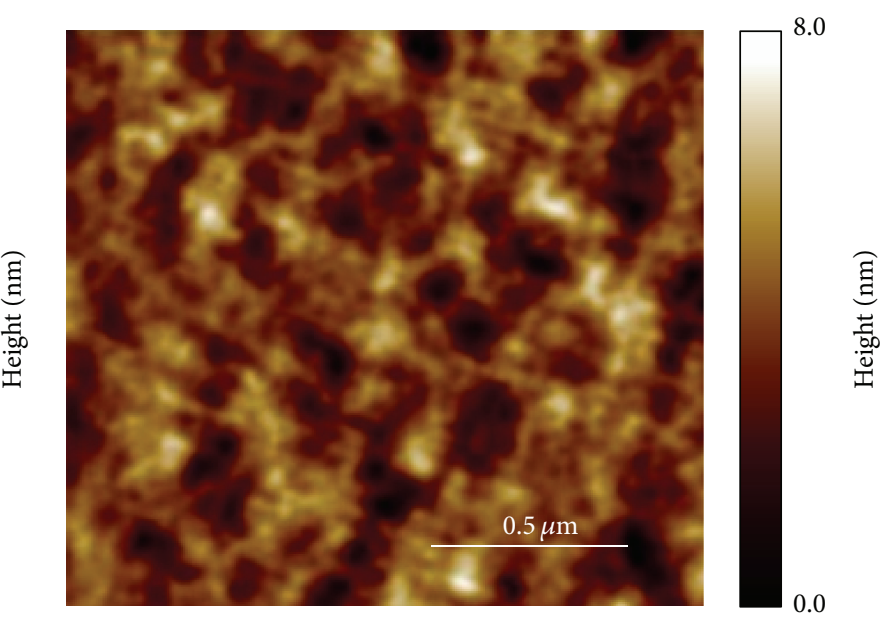

(b)

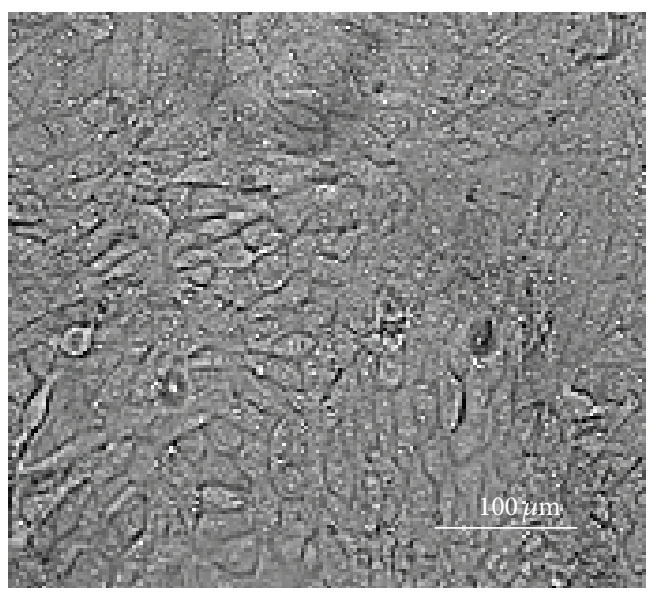

(c)

FIGURE 4: AFM images of PDMS OPM. Scan size of 5.0 (a) or $2.0 \mu \mathrm{m}$ (b) shows randomly distributed pores, with major diameter of (204 \pm $118) \mathrm{nm}$, expressed as values average $\pm \mathrm{SD}(n=60)$. Inverse light microscopy evaluation of cells cultured for $48 \mathrm{~h}$ within microchamber: $1.8 \times$ $10^{4} 3 \mathrm{~T} 3$ cells on the PDMS OPM (c).

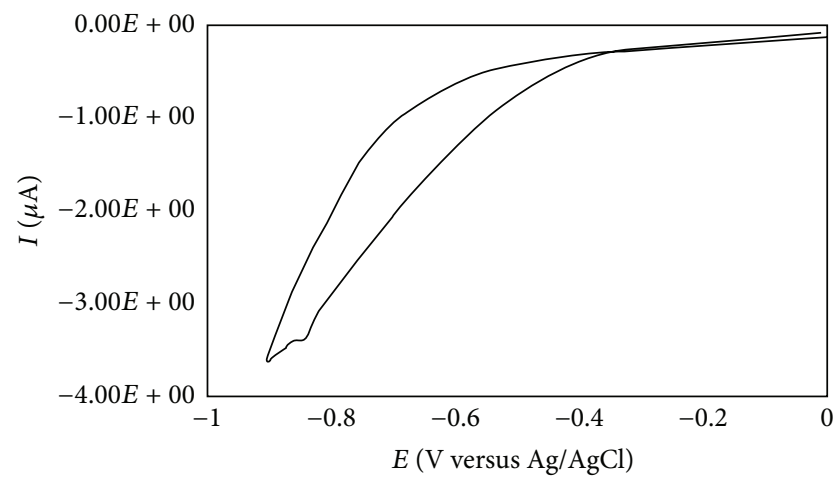

Figure 5: Cyclic voltammogram. Scan rate of $50 \mathrm{mV} / \mathrm{sec}$, in a $0.1 \mathrm{M}$ $\mathrm{KCl}$ solution.

within $300 \mathrm{sec}$, injecting $100 \mu \mathrm{L}$ of $0.1 \mathrm{M} \mathrm{Na}_{2} \mathrm{~S}_{2} \mathrm{O}_{4}$ solution in the microchamber after $100 \mathrm{sec}$ from the application of the potential. The recorded current assumes more positive values, indicating that the sodium dithionite solution has reduced most of the dissolved oxygen. The response time reaches a peak; then it stabilizes at a constant value.

This behavior is typically due to small amount of oxygen molecules, not reduced by the working sodium dithionite concentration, or by residual oxygen concentration in the electrolyte solution. Once all oxygen dissolved molecules are reduced, the current signal stabilizes at a minimum value, near to zero. Intensity value $\left( \pm \mathrm{Na}_{2} \mathrm{~S}_{2} \mathrm{O}_{4}\right.$ solution in the chamber expressed as $\Delta$ response) is $-0.54 \mu \mathrm{A} \pm$ $0.06 \mathrm{SD}$. Response times were calculated in terms of the time required to reach the peak value; MOD shows a $90 \%$ average response time of $39.6 \mathrm{sec}$. According to these results we attest a good reproducibility ( $\Delta$ current intensity: $0.54 \mu \mathrm{A} \pm 0.06 \mathrm{SD})$ and a quite short value for the response time $(\sim 40 \mathrm{sec})$, when relating to our larger PDMS oxygen permeable membrane thickness. The rate of diffusion across a membrane is governed by Fick's Law of diffusion, and the distance across the membrane is a critical parameter for the gradient rate ( $h$ is $80 \mu \mathrm{m}$ against $15 \mu \mathrm{m}$ and $20 \mu \mathrm{m}$ for the 
TABLE 1: Superficial roughness of $\mathrm{FeCl}_{3}$-treated $\mathrm{Ag}$ and $\mathrm{Au}$ electrodes.

\begin{tabular}{lcc}
\hline $\begin{array}{l}\text { Superficial } \\
\text { roughness } \\
\text { average values }\end{array}$ & $R_{a}=\frac{1}{N} \sum_{j=1}^{N}\left|Z_{j}\right|$ & $R_{q}=\sqrt{\frac{\sum Z_{j}^{2}}{N}}$ \\
\hline $\begin{array}{l}\text { Silver layer } \\
0.1 \mathrm{M} \mathrm{FeCl}_{3}\end{array}$ & $23.13 \pm 6.08 \mathrm{SD}$ & $28.4 \pm 6.94 \mathrm{SD}$ \\
$5 \mathrm{~min}$ & $26.27 \pm 1.06 \mathrm{SD}$ & $33.27 \pm 1.59 \mathrm{SD}$ \\
$50 \mathrm{mM} \mathrm{FeCl}_{3}$ & $2.01 \pm 0.14 \mathrm{SD}$ & $2.52 \pm 0.18 \mathrm{SD}$ \\
$50 \mathrm{sec}$ & & \\
$\quad$ Untreated & & \\
Gold layer & & \\
$50 \mathrm{mM} \mathrm{FeCl}$ & & \\
50 sec & $0.92 \pm 0.11 \mathrm{SD}$ & $1.18 \pm 0.15 \mathrm{SD}$ \\
$\quad$ Untreated & & $1.22 \pm 0.01 \mathrm{SD}$ \\
\hline
\end{tabular}

Average values, calculated by Nanoscope software v7.30 (Bruker). $R_{a}$ : arithmetic average of the absolute values of the surface height deviations measured from the mean plane; $R_{q}$ : root mean square average of height deviations taken from the mean image data plane.

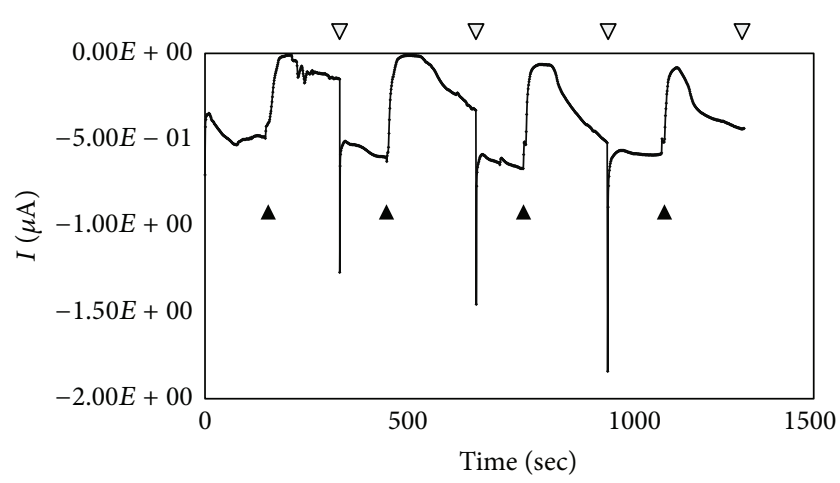

FIGURE 6: Amperometric response reproducibility. Response curves at $-0.8 \mathrm{~V}$ versus $\mathrm{Ag} / \mathrm{AgCl} \mathrm{RE}$, obtained by periodic injection (black arrows) and withdrawal (white arrows) of $\mathrm{Na}_{2} \mathrm{~S}_{2} \mathrm{O}_{4}$ solution from microoxygraph chamber inlet. $\Delta$ response: $0.54 \mu \mathrm{A} \pm 0.06 \mathrm{SD} ; 90 \%$ average response time is around $40 \mathrm{sec}$.

PDMS membrane applied, resp., by Wu et al. and Park et al. in $2010[25,27]$ ) (Table 2). The MOD was thus tested in order to assess its potentialities for biological application, such as cell metabolism screening in the presence of bioactive molecules, in in vitro disease models.

\subsubsection{Cell Oxygen Consumption Measurements. Cell cultures} were performed in the microchamber of the microoxygraph device. Before cell seeding, the microchamber was sterilized by $70 \%$ ethanol and double washed with PBS. The open upper inlet allows sample injection and medium and gas exchange during cell incubation. After $12 \mathrm{~h}$ of $3 \mathrm{~T} 3$ incubation, microelectrodes were quickly subjected to surface cleaning and chlorination treatments. Then, $0.1 \mathrm{M} \mathrm{KCl}$ electrolyte solution was injected in microchannel and OCR measurements were performed. A typical OCR $I / t$ curve is shown in Figure 7: cell response is recorded before and after $20 \mathrm{mM}$ sodium azide injection. Cells are viable and consume oxygen within microoxygraph chip. This is visible by the initial fast variation of current that moves towards lower values. In the presence of molecules that interfere with respiratory chain and aerobic metabolism, such as sodium azide, cells are prevented from using oxygen. Experimentally, after $100 \mu \mathrm{L}$ sodium azide solution injection, the initial current trend is congested: cellular respiration is inhibited, so that cells do not consume oxygen anymore and the current signal settles to a plateau (Figure 7(a)). As a result, in Figure 7(b), the 3T3 fibroblast morphology (on microoxygraph OPM) is clearly compromised after $20 \mathrm{mM} \mathrm{NaN}_{3}$ intoxication.

\section{Conclusions}

In summary, we reported on a disposable fluidic microoxygraph chip, a miniaturized electrochemical system for amperometric analysis of dissolved oxygen. Compared to traditional bench oxygraph, the disposable device displays miniaturization advantages, such as decrease of working volumes (samples, reagents from $200 \mu \mathrm{L}$ to $50 \mu \mathrm{L}$ ) and consequent reduction of operative outlay as well as fabrication costs (only tens of euro).

Comparative features of our and other interesting devices $[15,25,27]$ are detailed in Table 2 . We can assert that MOD shows performances comparable to the reported microsensors, with some additional advantages: it shows a large dynamic range ( $\Delta$ average current: $0.54 \pm 0.06 \mu \mathrm{A}$; residual current near to zero) and a good reproducibility of amperometric measurements (low SD). Response time ( $40 \mathrm{sec}$ ) could be lower, when relating to the larger PDMS oxygen permeable membrane thickness we adopted, with those reported in the literature ( $h$ is $80 \mu \mathrm{m}$ against $15 \mu \mathrm{m}$ and $20 \mu \mathrm{m}$ for the PDMS membrane applied, resp., by Wu et al. and Park et al. in $2010[25,27])$.

Another factor affecting the sensor analytical performance is the working electrode area. The current output is directly proportional to the sensor area. Supposing a uniform current distribution on the working microelectrode surface, in terms of surface charge density, the calculated $\sigma$ is $1.07 E-$ $13 ; 2.30 E-13$; and $2.98 E-14 \mathrm{C} / \mathrm{m}^{2}$, for our developed sensor and those described in $[25,27]$, respectively; in the present MOD, the higher cathode area should prevent susceptibility to noise. Nonetheless, the ease of use of microfluidic component, for internal reference electrode surface processing, results in a faster detector pretreatment just few minutes before electrochemical measurement.

Representative biological applications have upheld these evidences. By operating as microculture device too, it first allows cell adhesion and proliferation; then it permits low invasive sensing of cell metabolic activity in different conditions on the same chip. Biocompatible materials (glass and PDMS), utilized to fabricate the microoxygraph device, are advantageous for their transparency properties too, so that, during cell cultures, cells adhesion, spreading, and growth are easily morphologically monitored by a common inverse optical microscope.

The microsystem is suitable for microfluidic biosensor arrays configuration development. Future application for in vitro label-free investigation on drug-induced mitochondrial 
TABLE 2: Comparative table of different three-electrode configuration microoxygraphs functional features.

\begin{tabular}{|c|c|c|c|c|}
\hline Microoxygraphs & Current work & {$[15]$} & [25] & {$[27]$} \\
\hline Sample volume & $100 \mu \mathrm{L}$ & d.n.s. & d.n.s & $200 \mu \mathrm{L}$ \\
\hline Fluidic system & Yes & No & Yes & No \\
\hline Reducing agent $\left[\mathrm{Na}_{2} \mathrm{~S}_{2} \mathrm{O}_{4}\right]$ & $0.1 \mathrm{M}$ & $0.1 \mathrm{M}$ & $0.1 \mathrm{M}$ & $0.1 \mathrm{M}$ \\
\hline Cathode material/thickness (nm) & Gold 50 & Gold 400 & Gold 250 & Gold 250 \\
\hline Cathode area $\left(\mathrm{mm}^{2}\right)$ & 0.2 & 0.04 & 0.0004 & 0.025 \\
\hline Membrane material/thickness $(\mu \mathrm{m})$ & $\mathrm{PDMS} / 80$ & & $\mathrm{PDMS} / 15$ & $\mathrm{PDMS} / 20$ \\
\hline$\Delta$ average current & $0.54 \pm 0.06 \mu \mathrm{A}$ & nA (d.n.s.) & $7.09 \pm 0.09 \mathrm{nA}$ & $152.18 \pm 0.87 \mathrm{nA}$ \\
\hline Average $90 \%$ response time $(\mathrm{sec})$ & 39.6 & 40 & 13.4 & 4.9 \\
\hline
\end{tabular}

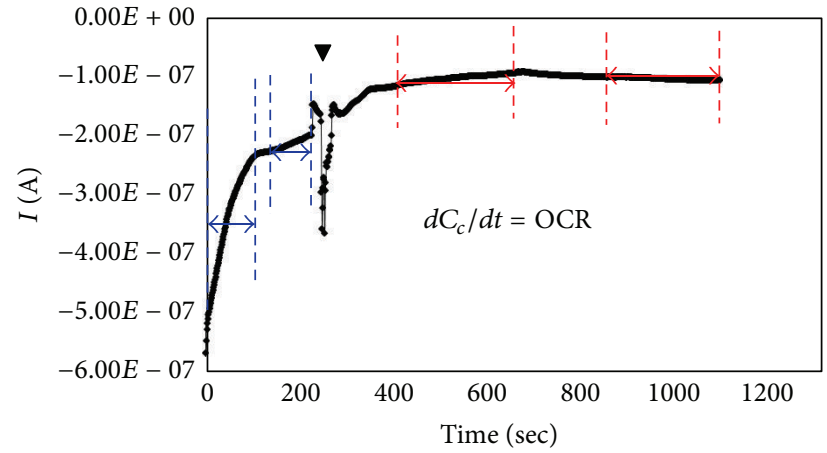

(a)

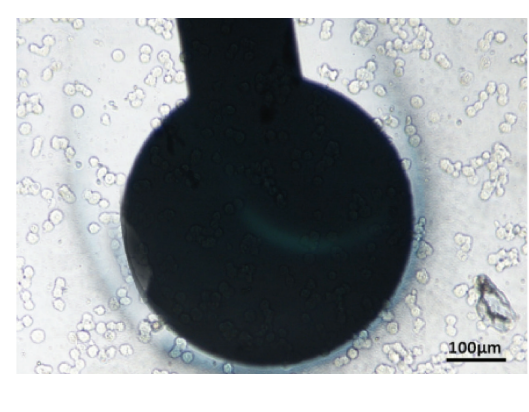

(b)

FIGURE 7: Typical cell OCR test by microoxygraph chip. 3T3 cells $\left(1.8 \times 10^{4}\right.$ cells/microchamber $)$ were seeded in microoxygraph chamber and incubated for $12 \mathrm{~h}$. After DMEM replacement with L15, amperometric measurements were performed. The recorded current is proportional to the dissolved oxygen concentration (directly) and to the cell OCR (inversely). The slope of oxygen concentration with time is defined as the oxygen consumption rate. Blue and red lines evidence the slopes before and after electron transport chain-inhibitor injection, respectively. Black arrow: $20 \mathrm{mM} \mathrm{NaN}_{3}$ injection. The recorded OCR, directly proportional to the number of active cells, is characterized by an initial high speed that slightly decreases after $150 \mathrm{sec}$. This positive $\mathrm{O}_{2}$ consumption trend is congested by $\mathrm{NaN}_{3}$ cell intoxication (a). Optical image of the 3T3 cells acquired after the recorded metabolic impairment. Plump morphology is observable in mitochondrial toxin damaged cells; cathode is clearly visible under cell culture OPM (b).

toxicity as well as on modulators of normal cellular metabolism can be performed with very low cell number and reagents amount within this device. As well, molecule interaction screening could be performed.

\section{Conflict of Interests}

The authors declare that there is no conflict of interests regarding the publication of this paper.

\section{Authors' Contribution}

A. Aloisi and E. Tarentini contributed equally to this work.

\section{Acknowledgments}

This work was partially supported by PONa3_00134 ONEV, PON02_00563 RINOVATIS, and Fondazione Cassa di Risparmio di Puglia.

\section{References}

[1] P. Jorjani and S. S. Ozturk, "Effects of cell density and temperature on oxygen consumption rate for different mammalian cell lines," Biotechnology and Bioengineering, vol. 64, no. 3, pp. 349356, 1999.

[2] D. C. Wallace, "A mitochondrial paradigm of metabolic and degenerative diseases, aging, and cancer: a dawn for evolutionary medicine," Annual Review of Genetics, vol. 39, pp. 359-407, 2005.

[3] J. Alderman, J. Hynes, S. M. Floyd, J. Krüger, R. O'Connor, and D. B. Papkovsky, "A low-volume platform for cell-respirometric screening based on quenched-luminescence oxygen sensing," Biosensors and Bioelectronics, vol. 19, no. 11, pp. 1529-1535, 2004.

[4] S. Andreescu, O. A. Sadik, D. W. McGee, and S.-I. Suye, "Autonomous multielectrode system for monitoring the interactions of isoflavonoids with lung cancer cells," Analytical Chemistry, vol. 76, no. 8, pp. 2321-2330, 2004.

[5] J. Park, Y. K. Pak, and J. J. Pak, "A microfabricated reservoirtype oxygen sensor for measuring the real-time cellular oxygen consumption rate at various conditions," Sensors and Actuators B: Chemical, vol. 147, no. 1, pp. 263-269, 2010. 
[6] T. Aoki, "Macromolecular design of permselective membranes," Progress in Polymer Science, vol. 24, no. 7, pp. 951-993, 1999.

[7] T. C. Merkel, V. Bondar, K. Nagai, and B. D. Freeman, "Sorption and transport of hydrocarbon and perfluorocarbon gases in poly(1-trimethylsilyl-1-propyne)," Journal of Polymer Science Part B: Polymer Physics, vol. 38, no. 2, pp. 273-296, 2000.

[8] S. A. Stern, "Polymers for gas separations: the next decade," Journal of Membrane Science, vol. 94, no. 1, pp. 1-65, 1994.

[9] T. C. Merkel, V. I. Bondar, K. Nagai, B. D. Freeman, and I. Pinnau, "Gas sorption, diffusion, and permeation in poly(dimethylsiloxane)," Journal of Polymer Science Part B: Polymer Physics, vol. 38, no. 3, pp. 415-434, 2000.

[10] A. Zanzotto, N. Szita, P. Boccazzi, P. Lessard, A. J. Sinskey, and K. F. Jensen, "Membrane-aerated microbioreactor for highthroughput bioprocessing," Biotechnology and Bioengineering, vol. 87, no. 2, pp. 243-254, 2004.

[11] Y. Nahmias, Y. Kramvis, L. Barbe, M. Casali, F. Berthiaume, and M. L. Yarmush, "A novel formulation of oxygen-carrying matrix enhances liver-specific function of cultured hepatocytes," The FASEB Journal, vol. 20, no. 14, pp. 2531-2533, 2006.

[12] M. Nishikawa, N. Kojima, T. Yamamoto, T. Fujii, and Y. Sakai, "An advanced in vitro liver tissue model by combination of onsite oxygenation and double-layer coculture with fibroblasts," AATEX, vol. 14, pp. 659-663, 2008.

[13] H. Shiku, T. Saito, C.-C. Wu et al., "Oxygen permeability of surface-modified poly(dimethylsiloxane) characterized by scanning electrochemical microscopy," Chemistry Letters, vol. 35, no. 2, pp. 234-235, 2006.

[14] H. Suzuki, A. Sugama, and N. Kojima, "Effect of anode materials on the characteristics of the miniature Clark-type oxygen electrode," Analytica Chimica Acta, vol. 233, no. 2, pp. 275-280, 1990.

[15] H. Suzuki, A. Sugama, and N. Kojima, "Miniature Clark-type oxygen electrode with a three-electrode configuration," Sensors and Actuators: B. Chemical, vol. 2, no. 4, pp. 297-303, 1990.

[16] H. Suzuki, N. Kojima, A. Sugama, and F. Takei, "Development of a miniature clark-type oxygen electrode using semiconductor techniques and its improvement for practical applications," Sensors and Actuators B: Chemical, vol. 2, no. 3, pp. 185-191, 1990.

[17] H. Suzuki, A. Sugama, and N. Kojima, "Micromachined Clark oxygen electrode," Sensors and Actuators B: Chemical, vol. 10, no. 2, pp. 91-98, 1993.

[18] H. Suzuki, A. Hiratsuka, S. Sasaki, and I. Karube, "Problems associated with the thin-film $\mathrm{Ag} / \mathrm{AgCl}$ reference electrode and a novel structure with improved durability," Sensors and Actuators B: Chemical, vol. 46, no. 2, pp. 104-113, 1998.

[19] H. Suzuki, H. Ozawa, S. Sasaki, and I. Karube, "Novel thinfilm $\mathrm{Ag} / \mathrm{AgCl}$ anode structure for microfabricated Clark-type oxygen electrodes," Sensors and Actuators B: Chemical, vol. 53, no. 3, pp. 140-146, 1998.

[20] H. Suzuki, "Advances in the microfabrication of electrochemical sensors and systems," Electroanalysis, vol. 12, no. 9, pp. 703-715, 2000.

[21] H. Suzuki, H. Arakawa, and I. Karube, "Fabrication of a sensing module using micromachined biosensors," Biosensors and Bioelectronics, vol. 16, no. 9-12, pp. 725-733, 2001.

[22] H. Suzuki, T. Hirakawa, I. Watanabe, and Y. Kikuchi, "Determination of blood $\mathrm{pO}_{2}$ using a micromachined Clark-type oxygen electrode," Analytica Chimica Acta, vol. 431, no. 2, pp. 249-259, 2001.
[23] C.-C. Wu, T. Yasukawa, H. Shiku, and T. Matsue, "Fabrication of miniature Clark oxygen sensor integrated with microstructure," Sensors and Actuators B: Chemical, vol. 110, no. 2, pp. 342-349, 2005.

[24] J. Wu, Z. Z. Ye, Y. Ying, and F. Ji, "The effect of the closelyspaced working and auxiliary electrodes on the performance of electrochemical oxygen sensor," Electroanalysis, vol. 19, no. 18, pp. 1939-1943, 2007.

[25] C.-C. Wu, H.-N. Luk, Y.-T. T. Lin, and C.-Y. Yuan, "A Clark-type oxygen chip for in situ estimation of the respiratory activity of adhering cells," Talanta, vol. 81, no. 1-2, pp. 228-234, 2010.

[26] J. Park, H. S. Kim, and A. Han, "Micropatterning of poly(dimethylsiloxane) using a photoresist lift-off technique for selective electrical insulation of microelectrode arrays," Journal of Micromechanics and Microengineering, vol. 19, no. 6, Article ID 065016, 2009.

[27] J. Park, Y. K. Pak, and J. J. Pak, "A microfabricated reservoirtype oxygen sensor for measuring the real-time cellular oxygen consumption rate at various conditions," Sensors and Actuators B: Chemical, vol. 147, no. 1, pp. 263-269, 2010.

[28] B. J. Polk, A. Stelzenmuller, G. Mijares, W. MacCrehan, and M. Gaitan, "Ag/AgCl microelectrodes with improved stability for microfluidics," Sensors and Actuators B: Chemical, vol. 114, no. 1, pp. 239-247, 2006.

[29] M. S. El-Deab and T. Ohsaka, "Quasi-reversible two-electron reduction of oxygen at gold electrodes modified with a selfassembled submonolayer of cysteine," Electrochemistry Communications, vol. 5, no. 3, pp. 214-219, 2003.

[30] J. Park, H. S. Kim, and A. Han, "Micropatterning of poly(dimethylsiloxane) using a photoresist lift-off technique for selective electrical insulation of microelectrode arrays," Journal of Micromechanics and Microengineering, vol. 19, no. 6, Article ID 65016, 2009.

[31] M. Juchniewicz, D. Stadnik, K. Biesiada et al., "Porous crosslinked PDMS-microchannels coatings," Sensors and Actuators B: Chemical, vol. 126, no. 1, pp. 68-72, 2007.

[32] H. Shiku, T. Saito, C.-C. Wu et al., "Oxygen permeability of surface-modified poly(dimethylsiloxane) characterized by scanning electrochemical microscopy," Chemistry Letters, vol. 35, no. 2, pp. 234-235, 2006.

[33] G. Mehta, K. Mehta, D. Sud et al., "Quantitative measurement and control of oxygen levels in microfluidic poly(dimethylsiloxane) bioreactors during cell culture," Biomedical Microdevices, vol. 9, no. 2, pp. 123-134, 2007.

[34] S. Bhattacharya, A. Datta, J. M. Berg, and S. Gangopadhyay, "Studies on surface wettability of poly(dimethyl) siloxane (PDMS) and glass under oxygen-plasma treatment and correlation with bond strength," Journal of Microelectromechanical Systems, vol. 14, no. 3, pp. 590-597, 2005.

[35] A. Aloisi, E. Tarentini, G. Leopizzi, R. Rinaldi, A. Ferramosca, and V. Zara, "Oxygraph chamber and insertable micro-culture device and uses thereof," European Patent EP2597148, 2013. 


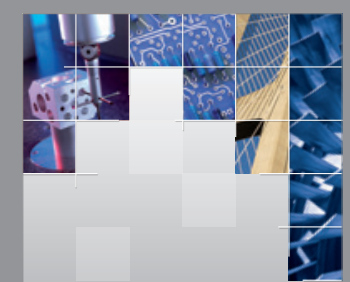

\section{Enfincering}
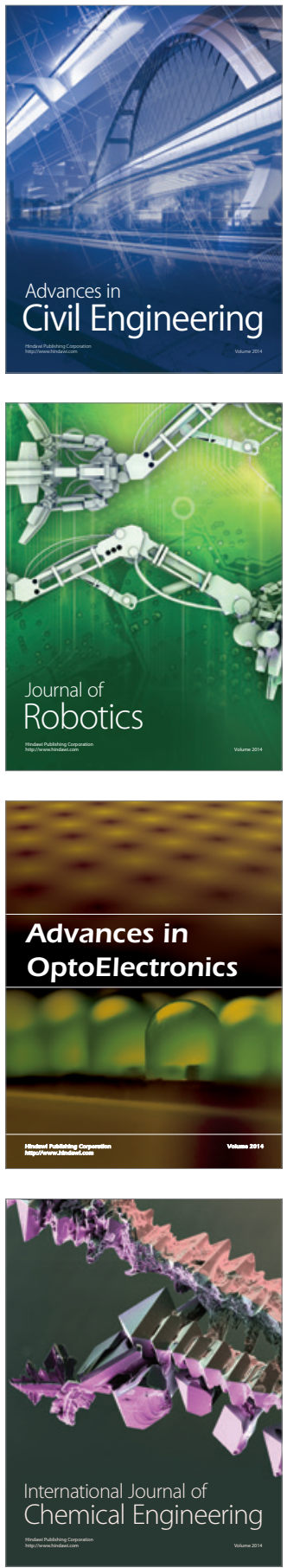

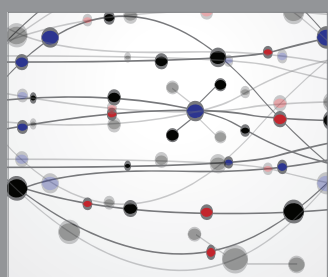

The Scientific World Journal

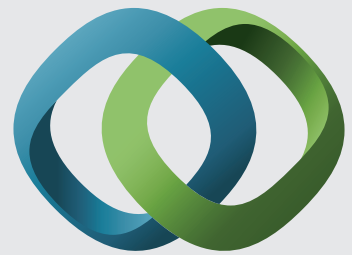

\section{Hindawi}

Submit your manuscripts at

http://www.hindawi.com
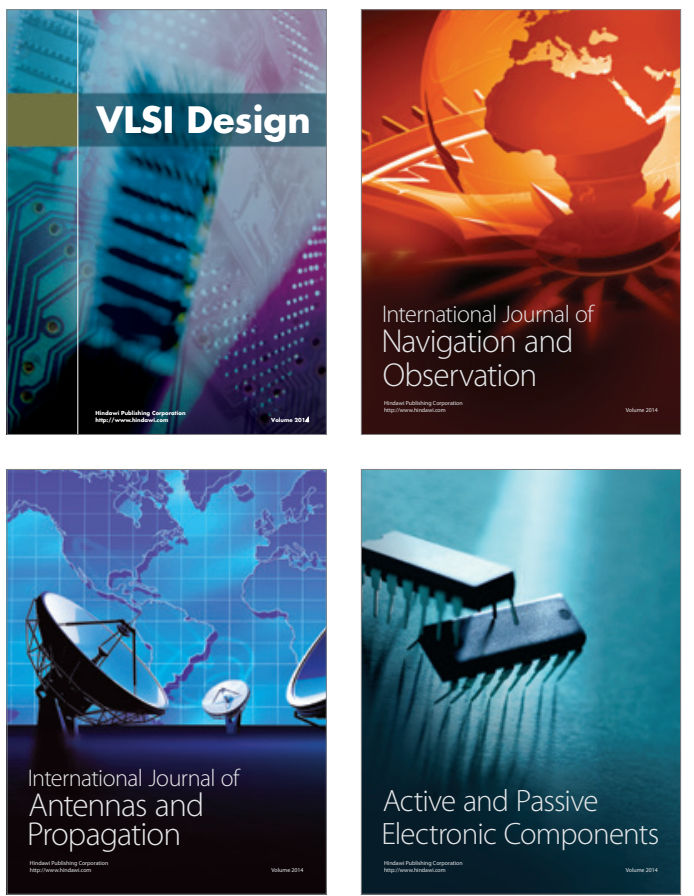
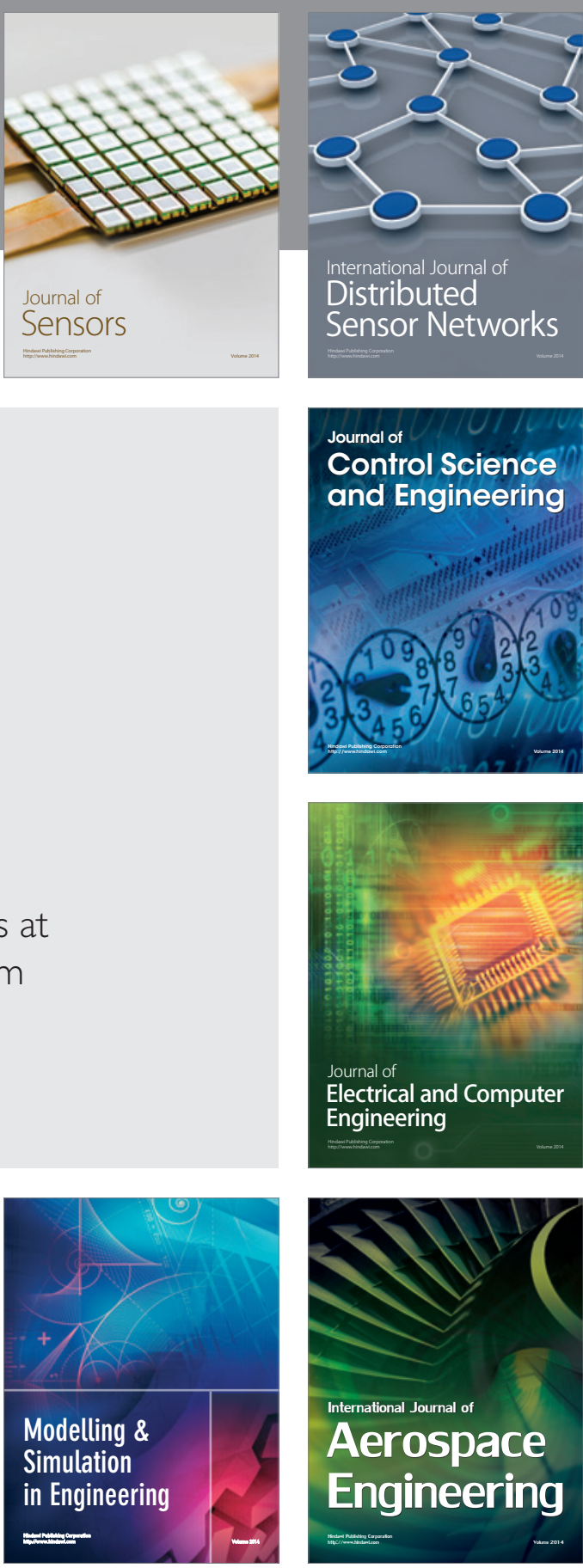

International Journal of

Distributed

Sensor Networks

Journal of

Control Science

and Engineering
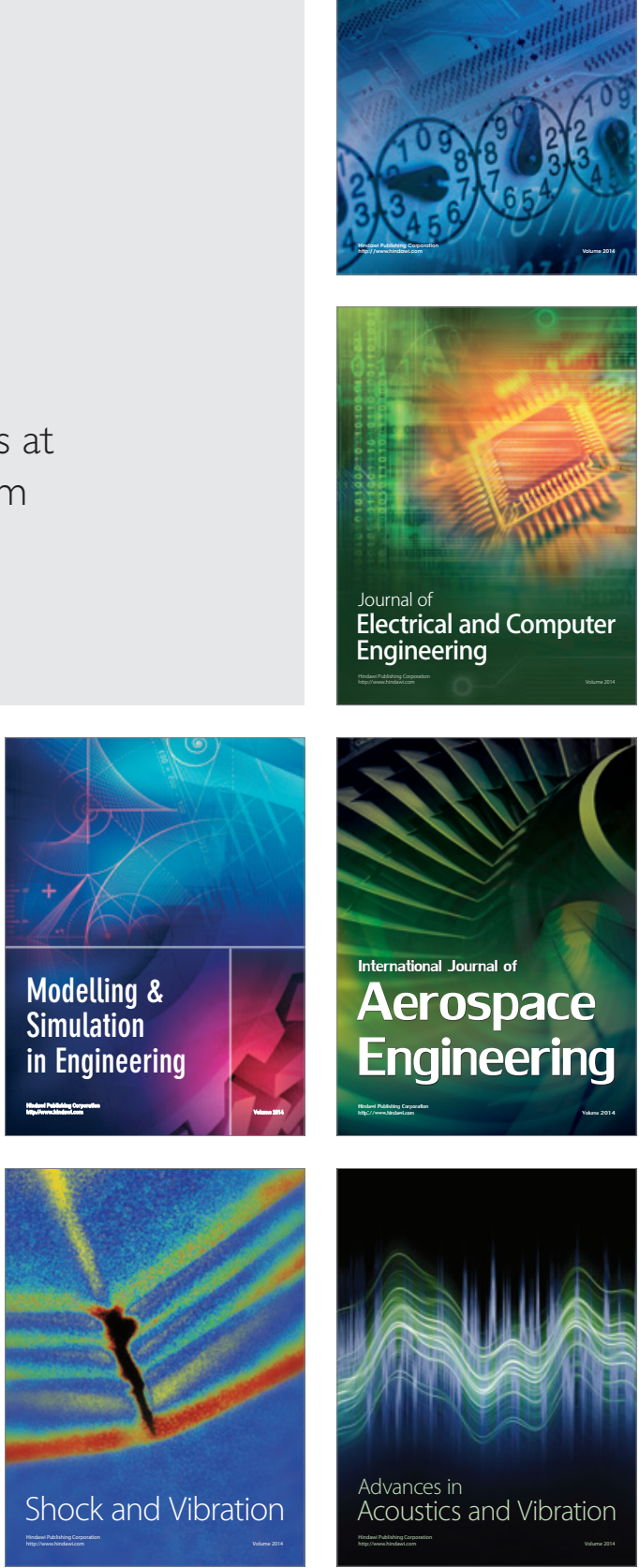